\title{
PAISAGEM COMO OBJETO SEMIÓTICO: ECOMOSAICO
}

\author{
landscape as a semiotic object: ecomosaic
}

\author{
José Armando Pinto Casquilho * \\ Rodrigo Aleixo Brito de Azevedo **
}

\begin{abstract}
Resumo
Neste trabalho cita-se um conjunto de referências que revisitam e discutem a paisagem como objeto de percepção e de interpretação em várias ciências, salientando-se a Geografia, a Ecologia e a Semiótica. Enquanto objeto semiótico a paisagem revela-se em conjuntos de valores ordenados, ou ordenáveis, em quadros perceptivos, conjugando aspectos reais e simbólicos, materiais e ideológicos, a que se podem associar métodos do esquema tensivo de interpretação e de diagnóstico, portanto de significação. A paisagem georreferenciada expressa-se em matrizes semióticas e o conceito de ecomosaico permite uma redução lata, multidimensional, que não esgota o tema mas visa ancorá-lo na dupla perspectiva da composição e da configuração, ou seja da constituição do padrão e da aferição de valores característicos do território, nomeadamente econômicos e ecológicos. Podem-se acoplar modalidades tensivas, quer na apreciação da diversidade ou na análise da sustentabilidade e da resiliência da paisagem. A dicotomia paisagem/espaço de Milton Santos é geradora de semiose múltipla ressaltando-se a síntese do espaço definido como uma reunião dos fixos e dos fluxos, do qual a paisagem é expressão sincrônica, revelando uma dialética entre cultura e natureza.
\end{abstract}

Palavras-chave: Espaço, Território, Dicotomias, Significação, Milton Santos.

\begin{abstract}
This work seeks to review a set of references that revisit and discuss landscape as an object of perception and interpretation in the Sciences of Geography, Ecology and Semiotics. While landscape as a semiotic object may be acknowledged as sets of values ordered in perceptive frames, combining real and symbolic aspects, material and ideological features, which can evoke tensive schemas methods of interpretation and therefore diagnosis and signification. Geo-referenced landscape mosaics express as semiotic resources, and the concept of ecomosaic allows for a wide, multidimensional reduction, that does not exhausts the theme but anchors it in the double perspective of the analysis of composition and configuration as constitutional facets of the pattern, benchmarking characteristic values of the territory, namely ecological and economic. We may consider tensive modalities either through the assessment of diversity or the analysis of sustainability and resilience of the landscape. The dichotomy landscape/space of Milton Santos generates multiple semiosis concerning the synthesis of space defined as a set of fixed elements and flows, from which landscape emerges as a synchronous expression, revealing the dialectics between culture and nature.
\end{abstract}

Key words: Space, Territory, Dichotomies, Signification, Milton Santos.

\section{Résumé}

Dans ce travail on cherche à organiser un ensemble de références lesquelles revisitent et questionnent le paysage comme objet de perception dans les sciences de la Géographie, de l'Écologie et la Sémiotique. En tant que ressource sémiotique le paysage s'exprime au moyen d'ensembles de valeurs commandées dans des visions, tableaux perceptifs, auxquels peuvent être reliées des méthodes du schèma tensif d'interprétation et de diagnostic, donc de signification. Les paysages géoréférencés s'expriment comme ressources sémiotiques et le concept d'éco-mosaïque permet une réduction large, multidimensionnelle, qui ne pas épuise le thème mais fait son ancrâge dans la double perspective des sujets de la composition et de la configuration de la mosaïque, évaluant des valeurs caractéristiques du territoire, notamment écologiques et économiques. Nous pouvons considérer l'application des modalités tensives, soit par le biais de l'appréciation de la diversité, de la durabilité ou de la résilience du paysage. La dichotomie paysage/l'espace de Milton Santos génère plusieurs signifiés en particulier la synthèse de l'espace définit comme un ensemble des éléments fixes et des flux, d'où le paysage émerge comme une expression synchrone, révélant la dialectique de la nature et de la culture.

Mots-clés: Espace, Territoire, Dichotomies, Signification, Milton Santos.

(*) Prof. Dr. do Programa de Pós-Graduação e Pesquisa da Universidade Nacional Timor Lorosa'e (UNTL) - Av. Cidade de Lisboa, Díli, Timor-Leste. Tel: (+670) 3310446. - josecasquilho@gmail.com

(**) Prof. Dr. da Universidade de Integração Internacional da Lusofonia Afro-brasileira (UNILAB) - Avenida da Abolição, $\mathrm{n}^{\circ}$ 03 - Centro, CEP: 62.790-000, Redenção (CE), Brasil. Tel (+ 55 85) 3332.1155. - rodrigo_azevedo@unilab.edu.br 


\section{INTRODUÇÃO}

Paisagem e espaço não são sinônimos. A paisagem é o conjunto de formas que, num dado momento, exprimem as heranças que representam as sucessivas relações localizadas entre homem e natureza. $\mathrm{O}$ espaço são essas formas mais a vida que as anima. (SANTOS, 2002)

A paisagem como signo - ou seja, algo que significa no lugar de alguma outra coisa-, remete desde logo para uma imagem extensa, a que sucede um conjunto de implicações: o rio é bordejado por prados, tem floresta ou casario num entremeado de hortas, até pode ser só cidade, paisagem urbana, deserto ou gelo. Em qualquer caso aparece-nos como uma extensão visível do espaço geográfico. Foi a representação icônica que lhe deu suporte comunicacional, surgindo depois como um conjunto de símbolos e um feixe de apontadores, índices, formando uma deixis: o relevo mostra uma energia geomorfológica que se foi desdobrando localmente, enquanto que o manto vegetal fala do clima, do solo, da sucessão ecológica e da ação do homem. Os monumentos e as vias de comunicação podem ser nomeados como pontuação simbólica.

Também pois se pode falar da paisagem como uma linguagem, formada por encadeados de elementos, sejam sintagmas, como por exemplo sebes, ou reticulados de culturas agrícolas, interpretáveis como símbolos relativos a valores especificados numa cultura, e assim está-se colocado perante a tríade com que Peirce caracterizou o conjuntos dos signos: símbolo, fixado por convenção numa comunidade interpretante; índice, que indica algo por uma implicação física ou mental; e ícone, que estabelece uma relação de semelhança imediata com o objeto. O signo na definição clássica é algo que está no lugar de uma outra coisa, aliquid stat pro aliquo, (ECO, 1994, pag.11) e gera um processo de interpretação, de convocação e encadeamento de significados, designado por semiose.

Para explorar o objeto paisagem a dicotomia ou par dialéctico espaço/paisagem elaborada por Milton Santos (e. g. 1994) é particularmente rica na geração de referências e relações, onde ressalta como essência o espaço animado das relações vitais, econômicas, sociais. Salienta-se o seguinte enunciado:

(...) tanto a paisagem quanto o espaço resultam de movimentos superficiais e de fundo da sociedade, uma realidade de funcionamento unitário, um mosaico de relações, de formas, funções e sentidos. (Santos, 1988, p: 21).

\section{PAISAGEM E TERRITÓRIO}

Num dicionário de Geografia lemos o seguinte enunciado (SMALL e WITHERICK, 1992): paisagem define-se como o conceito usado para descrever o aspecto global de uma área, sendo a paisagem cultural produzida pela ocupação humana onde o ambiente físico fornece o habitat e a cultura é o agente que condiciona a sua modificação. Paisagem é uma palavra da língua portuguesa proveniente do legado latino: um pagus era uma demarcação rural do Império Romano consistindo num povoado e terras circundantes, habitada por pagãos, camponeses. Por agregação sucessiva origina paisagem e país, e termos semelhantes em espanhol e em francês (paysage, pays), em qualquer caso sob a alçada do vínculo etimológico pak, referido como raiz indo-europeia de pacto e de paz (LEPECKI, 2001).

A paisagem é desde o século XIX objeto de análise e pesquisa na Geografia tal como Humboldt a introduziu, produto do embate entre as cosmovisões materialista e idealista, onde a idéia principal está na perspectiva de unidade (VITTE \& SILVEIRA, 2010). Norberg-Schultz (1976, p: 46) diz-nos que Ludwig Curtius referia a paisagem como uma totalidade compreendida (geschlossenes Gebilde), na esteira do pensamento filosófico alemão da época liderado por Kant, onde se dava acento à percepção como acto unitário: o todo apreende-se antes das partes. Colocando estas 
referências estamos subscrevendo o enunciado de que a compreensão do pensamento geográfico através do tempo histórico passa pela compreensão do pensamento filosófico e o desenvolvimento do olhar geográfico possibilita um hábito de observar, de especular, de tentar a decifração do espaço (PEREIRA, 2006).

Uma definição clássica refere a paisagem como o espaço acessível à observação que apresenta, para além dos factos visíveis, a marca de muitos outros, de diferentes categorias, que influenciam e explicam os primeiros (RIBEIRO, 2001) e assim também constitui um símbolo ou conjunto de sinais a interpretar (GASPAR, 2001). Pode-se indagar mapas de espacialização de manifestações culturais, seja a dança de roda no Sergipe observada numa matriz semiótica (ALMEIDA et al., 2011), afinal paisagens de signos.

Espaço e paisagem são frequentemente confundidos, mas paisagem é espaço geográfico investido de significação imediata, não há paisagem fora do olhar humano, e este é condicionado pela visão cultural dos sujeitos de percepção de que a paisagem é imagem, mais fixa que móvel. Numa síntese, a paisagem é a expressão sensível de uma larga trama de interrelações entre a sociedade e o território (CHIOZZA e CARBALLO, 2006), podendo ser entendida como um conjunto de valores ordenados numa visão (CAUQUELIN, 2008, pag.14). Ainda podemos dizer que se está perante uma metonímia - uma metáfora por contiguidade com o referente através do vínculo territorial -, das relações entre natureza e cultura.

Há autores que consideram que a tradução recíproca entre as línguas portuguesa e inglesa das palavras paisagem/landscape denota o mesmo objeto de percepção, definido como uma região do espaço geográfico que se estende até onde a vista alcança, mas por via de diferentes conotações: no termo anglófono através de uma versão arcaica pode dizer-se que a terra escapa. Já Amaral (2001) refere que o termo ancestral inglês para landscape era landscipe, usado para designar um território pertencente a um senhor ou habitado por um grupo particular de gente. Dá-nos notícia Zonneveld (1990) de que o termo landscape teria provindo da palavra holandesa landschap, uma parcela de área agrícola demarcada, que informa a tradição holandesa de pintura de paisagens, com um impacto forte na iconografia dos séculos XV e XVI, passando de fundo a primeiro plano como objeto icônico. Holzer (1999, p. 152) diz que:

“a palavra alemã 'Landschaft' se refere a uma associação entre sítio e os seus habitantes, ou se preferirmos, de uma associação morfológica e cultural. Talvez tenha surgido de'Land schaffen', ou seja, criar a terra, produzir a terra. Esta palavra transmutada em 'landscape' com o sentido de formatar (land shape) a terra, implicando numa associação das formas físicas e culturais".

Carl Troll, geógrafo alemão, nos anos trinta do século passado, introduziu a expressão ecologia da paisagem, nascendo aquilo que se caracterizou como uma disciplina formada no casamento entre as ciências da Ecologia e da Biologia - agora as interações nas comunidades bióticas apresentavam-se integradas em unidades territoriais representadas num mosaico de fotografias aéreas. A palavra ecologia tinha o seu assentamento desde cerca de 1866 quando o biológo alemão Ernst Haeckel definiu a ciência que estuda as relações dos organismos com o meio e o mundo exterior.

Uma definição recente de Ecologia da Paisagem estabelece que é a ciência e a arte de estudar e influenciar a relação entre padrões espaciais e processos ecológicos através de diferentes níveis hierárquicos da organização biológica e diferentes escalas no espaço e no tempo (WU e HOBBS, 2007). Houet et al. (2010) salientam que a dimensão temporal das paisagens é tão importante quanto a espacial, quando se visa monitorizar, modelar e compreender as interações entre cultura e natureza e identificar as forças diretoras.

Dir-se-á que a maior contribuição que a ecologia trouxe ao objeto geográfico paisagem foi enfatizar as dinâmicas, o aspecto diacrônico: as paisagens mudam quando observadas em documentos com idades diferentes, e essa observação fez amplificar o conceito de mosaico de paisagem em metamorfose, chamando assim a teoria dos sistemas dinâmicos de que a ecologia das populações e das comunidades eram legatárias. A ecossistémica é um processo de análise da realidade e um 
modelo de representação que foi construído para apreender relações bióticas (DEVY-VARETA, 1995, p: 153). No entanto a paisagem georreferenciada continua a ser objeto geográfico, agora, para além de complexo, hiperdimensional.

Os gregos habitavam o khoros, território, inserido na khóra, região, e concebiam a paisagem como unidade delimitada que se expressava na beleza do arranjo e das proporções, e de que o Olimpo, a floresta sagrada no topo das montanhas, era o exemplo a emular. Segundo a etimologia, khoréma deriva do verbo khoréo: dar espaço para algo. Existe uma relação de carácter geral que liga a natio, a polis e a physis dos Gregos: a da proporção e da harmonização recíproca das partes (MICHELI, 1990, p: 12). Por outro lado a raíz latina do verbo terrere está ligada aos significados de assustar, afastar, denotando espaço a defender.

O conceito de território é substituído em certa medida pelo da percepção do espaço, onde as formas se expressam sobre um fundo, têm uma disposição e portanto uma sintaxe, e esta revela significados, uma semântica. Desde o Neolítico, se não antes, que o homem habita um lugar em que consegue orientar-se e experimentar a significação de um meio, incluindo a sustentação. Instalar-se num território equivale, em última instância, a consagrá-lo (ELIADE, 2001, p: 36), torná-lo o centro do mundo, o ponto fixo, ligando-o ao transcendente por rituais simbólicos; o centro é pois a zona do sagrado por excelência, da realidade absoluta (ELIADE, 1981, p: 32).

Numa perspectiva agrícola é dentro da paisagem que o agricultor demarca seu território, e associados a este estão um conjunto de recursos indispensáveis à reprodução das unidades de produção (AZEVEDO, 2007). No seu sentido mais lato o território define uma zona de competência determinada por uma superfície, uma forma e limites (RONCAYOLO, 1986, p: 262).

\section{PAISAGEM COMO OBJETO SEMIÓTICO}

A semiótica define-se em vários planos mas enquanto teoria constitui uma teoria da significação (GREIMAS e COURTÉS, 2008, p: 455) e o escopo da semiótica não é reduzir o múltiplo a uma única teoria, mas afirmar o múltiplo, articular as diferenças e compreender os processos de significação pois semiotizar não é ver mas interpretar (MOURÃO e BABO, 2007, p: 224). Se consideramos a paisagem como objeto semiótico é pertinente recordar a dicotomia forma pregnante/forma saliente que René Thom introduziu no âmbito dos modelos matemáticos da morfogênese (THOM, 1980) e que Petitot resumiu dizendo que os semas profundos são pregnâncias e as saliências manifestam-se como singularidades (PETITOT-COCORDA, 1992, p: 374).

Pode-se associá-la à dicotomia entre paisagem e espaço trabalhada por Milton Santos, fazendo a seguinte correlação: a forma saliente expressa-se na paisagem enquanto a forma pregnante é o espaço animado das relações vitais. Vai no mesmo sentido a apreciação de que à paisagem como expressão sensível de mosaicos, aqui entendidos enquanto sistemas espacialmente organizados, se poderá aplicar o enunciado de Deleuze (2006, p: 107): a superfície é o lugar do sentido, os signos permanecem desprovidos de sentido enquanto não entram na organização de superfície que assegura a ressonância de duas séries.

Falar de valores convoca outros conceitos. Desde logo a palavra valor tem a sua origem na denotação da valentia de um guerreiro associado aos radicais latinos 'vir', origem de varão, e 'vis', força, a que se associa 'virens', verde, este associado à força da folhagem na Primavera dos climas mediterrânicos. Numa síntese ilustrativa destes termos afirma-se: a floresta tem valor pelo simples fato de existir (CASTRO, 2002, p: 184).

$\mathrm{Na}$ economia Karl Marx estabeleceu a dicotomia das categorias valor de uso/valor de troca, e Ferdinand de Saussure, por volta de 1916, transpôs para a linguística essa dualidade através do par significante/significado do signo linguístico, ainda correlacionando com a necessidade de distinguir os valores considerados em si desses mesmos valores considerados em função do tempo, expressos na dicotomia sincronia/diacronia (SAUSSURE, 1999). 
Tomando como referência o termo 'mapa' na sua acepção corrente, um documento cartográfico vetorial, trata-se de um desiderato principalmente icônico havendo que enfatizar que agora não há apenas uma dimensão linear de leitura, mas várias: uma linguagem planar que remete na legenda para outras dimensões, e onde os elementos pictóricos articulam-se em semas icônicos no contexto de um código. A valoração na paisagem pode ser representada num diagrama de estrutura tensiva no sentido em que Fontanille e Zilberberg (2001) utilizaram o conceito, por exemplo aplicado ao confronto entre valores reais e simbólicos na paisagem: uns extensivos, outros intensivos.

Também Domingues (2001) refere que sobre paisagens em tensão produzem-se discursos que reflectem conflitos de representação, de uso, ou de (re)apropriação. Gilberto Freyre (1961, p: 54/55) conta a história da civilização do açúcar no Nordeste brasileiro, e afirma que a floresta tropical foi um obstáculo, devastada pelo colonizador no interesse quase exclusivo da monocultura da cana ou da metrópole faustosa, enquanto que o colonizador negro adaptou-se em parte à floresta e em parte adaptou a floresta às suas necessidades. Tem-se um exemplo estudado recentemente como sejam as comunidades quilombolas da Paraíba, onde se conclui que a memória, a tradição enraízada no espaço geográfico, constitui direitos que campeiam na relação de forças e tensões sociais, econômicas e políticas de uma região (RODRIGUES, 2011).

\section{MOSAICO DE PAISAGEM E ECOMOSAICO}

Mosaico é um termo que tem a sua raíz etimológica na palavra musa, e tornou-se tema dominante da apreciação contemporânea da paisagem nas perspectivas ecológica e geográfica. O conceito de mosaico nos estudos da natureza começou por ser aplicado profusamente por Braun-Blanquet e seus discípulos, a propósito dos estudos fitossociológicos em comunidades vegetais, na sequência de trabalhos de Du Rietz reportados à década de vinte do século passado. Milton Santos (1988) diz-nos que a paisagem é um palimpsesto.

A mutação do mosaico de paisagem em períodos de décadas, ou mais, é tema atual de pesquisa intensa. Por exemplo, Riitters et al. (2009) utilizam um indicador de composição da paisagem que classifica um pixel numa de 19 categorias atendendo ao que acontece numa vizinhança, utilizando uma escala triádica de referência, a que se associam processos estocásticos, para discernir mecanismos de transição e metamorfose; Diaz-Varela et al. (2009) na Galiza espanhola utilizaram 24 classes para distinguir o uso do solo corrente e estados de transição na paisagem e aferir unidades de planejamento.

Ecomosaico é um termo cunhado originalmente em língua inglesa referindo um paradigma de estrutura da paisagem composta por elementos (FORMAN, 1995, p: 300) com conteúdo semelhante a mosaico de paisagem, e escalas definidas por NAGENDRA e GADGIL (1999) na amplitude $10^{8}-10^{10} \mathrm{~m} 2$, inseridos nas ecorregiões e compostos por ecótopos. O termo está introduzido na língua portuguesa pelo menos desde o final do século passado, relativo a índices de diagnóstico da composição da paisagem (CASQUILHO, 1999) ou na caracterização fisiográfica de matos de capoeira baixa em floresta umbrófila (AMADOR e VIANA, 2000). O termo também existe na língua francesa, referido como o nível hierárquico superior onde ocorrem as eco-unidades no âmbito da análise da arquitectura e da biodiversidade florestais (SCHNITZLER, 2001). Acresce que o termo comporta várias conotações a partir do momento que invoca os processos acoplados ao padrão e subtende uma caracterização em valores ecológicos ou em valores econômicos, por exemplo custos de reconstituição de habitats como seja no caso do diagnóstico efectuado pelos índices definidos como utilidades esperadas (CASQUILHO, 2011, 2012).

\section{DISCUSSÃO}

Springer (2010) considera que a relação intrínseca e indissociável entre história, filosofia, conhecimento científico e concepção da Natureza origina tipologias que relevam de quatro categorias: 
a physis na Grécia antiga, a natureza divinizada, a natureza mecânica e racional e finalmente uma questão que subsume novas teorias - que Natureza é essa? Anne Cauquelin (2008, p: 52) afirma que a paisagem é uma substância e a questão, e a tensão, no caso da paisagem, coloca-se em torno da distinção entre imagem natural e imagem artificial, recordando-se que para Aristóteles a substância caracterizava-se pelo menos em quatro acepções, a saber: a essência, o universal, o gênero e o substrato (ZILLIG, 2007).

O conceito de ecomosaico pode ser um mediador entre a paisagem expressa e o espaço pregnante, acoplando fixos e fluxos e permitindo pesquisar aspectos invisíveis ou implícitos em torno dos dispositivos de caracterização das variedades de equilíbrios de composição e sua dinâmica. Num formalismo matemático pode dizer-se que mergulhar o espaço geográfico imanente num espaço euclideano n-dimensional permite uma outra análise, onde os teoremas das funções implícitas ocupam lugar proeminente (e.g. LIMA, 1970), podendo os enunciados ser transpostos para espaços normados mais gerais. Recorda-se que o valor no sentido semiótico é o valor como diferença que organiza cognitivamente o mundo focalizado (FONTANILLE e ZILBERBERG, 2001, p: 29) e que o sentido é, em primeiro lugar, uma direção, pois dizer que um objecto ou uma situação tem um sentido é dizer que tende a algo (FONTANILLE, 2007, p: 31).

\section{REFERÊNCIA BIBLIOGRÁFICA}

ALMEIDA, M. G.; VARGAS, M. A. M.; MENDES, G. F. Territórios, paisagens e representações: um diálogo em construção. Mercator, Fortaleza, v. 10, n. 22, p.23-35, 2011.

AMADOR, D. B., VIANA, V. M. Dinâmica de capoeiras baixas na restauração de um fragmento florestal. Scientia Forestalis n. 57, p. 69-85, 2000.

AMARAL, I. Àcerca de «paisagem»: apontamentos para um debate. Finisterra, v. 36, n. 72, p. 75-81, 2001. AZEVEDO, R. A. B. Análise e descrição de sistemas agrícolas: teorias para a não naturalização da agricultura. Revista Verde, v.2, n.2, p. 01-26, 2007.

CASQUILHO, J.A.P. Ecomosaico: Índices para o Diagnóstico de Proporções de Composição (Tese de Doutorado em Engenharia Florestal), 205 p., Lisboa: Universidade Técnica de Lisboa, Instituto Superior de Agronomia, 1999.

CASQUILHO, J. P. Composição de ecomosaicos e indices de utilidade esperada. Silva Lusitana v. 19, n.1, p. 55-65, 2011.

CASQUILHO, J. A. P. Ecomosaico florestal: composição, índices de informação e abdução. Rev. Árvore, vol.36, n.2, p. 321-329, 2012.

CASTRO, C. F. A. Gestão Florestal no Brasil Colônia (Tese de Doutorado em Políticas Públicas e Gestão Ambiental), 200 p., Brasília: Universidade de Brasília, Centro de Desenvolvimento Sustentável, 2002.

CAUQuelin, A. A Invenção da Paisagem. Lisboa: Edições 70, 2008, 151 p.

CHIOZZA, E.; CARBALLO, C. Introduccíon a la Geografía. Bernal: Universidade Nacional de Quilmes Editorial, 2006,160 p.

DELEUZE, G. Lógica do Sentido. São Paulo: Editora Perspectiva S. A., 2006, 342 p.

DEVY-VARETA, N. Uma perspectiva da Geografia: do social ao natural, passando pelo ambiente vegetal... In A Geografia Portuguesa: debater as mudanças, preparar o futuro, Actas do II Congresso da Geografia Portuguesa, vol. 1, p. 149-156, Lisboa: Associação Portuguesa de Geógrafos, 1995.

DÍAZ-VARELA, E.; ÁLVAREZ-LÓPEZ, C. J.; MAREY-PÉREZ, M. F. Multiscale delineation of landscape planning units based on spatial variation of land-use patterns in Galicia, NW Spain. Landscape Ecol Eng v. 5, 2009, p. 1-10.

DOMINGUES, A. A paisagem revisitada. Finisterra, v. 36, n. 72, p. 55-66, 2001.

ECO, U. Signo. Enciclopédia Einaudi: Signo, (coord: F Gil) v. 31, pp: 11-51. Lisboa: Imprensa Nacional Casa da Moeda, 1994. 
ELIADE, M. O Sagrado e o Profano: A Essência das Religiões. São Paulo: Livraria Martins Fontes, 2001, $191 \mathrm{p}$.

ELIADE, M. O Mito do Eterno Retorno. Lisboa: Edições 70, 1981, 175 p.

FONTANILLE, J. Semiótica do Discurso. São Paulo: Editora Contexto, 2007, 288 p.

FONTANILlE, J; ZILBERBERG, C. Tensão e Significação. São Paulo: Discurso Editorial, 2001, 331 p. FORMAN, R. T. T. Land Mosaics: The Ecology of Landscapes and Regions. Cambridge: Cambridge University Press, 1995, 632 p.

FREYRE, G. Nordeste : Aspectos da Influência da Cana sobre a Vida e a Paisagem do Nordeste do Brasil (3 ${ }^{\mathrm{a}}$ ed.), Rio de Janeiro: Livraria José Olympio Editora, 1961, 183 p.

GASPAR, J. O retorno da paisagem à geografia. Apontamentos místicos. Finisterra, v. 36, n. 72, p. 83-99, 2001.

GREIMAS, A. J., COURTÉS, J. Dicionário de Semiótica. São Paulo: Contexto, 2008, 544 p.

HOLZER, W. Paisagem Imaginário e identidade: alternativas para o estudo geográfico. In: ROSENDAHL, Z. e CORRÊA, R. L. (orgs). Manifestações da Cultura no Espaço. Rio de Janeiro: Eduerj, 1999, p.149-168. HOUET, T.; VERBURG, P. H.; LOVELAND, T. R. Monitoring and modelling landscape dynamics. Landscape Ecology, v. 25, p. 163-167, 2010.

LEPECKI, M. A mãe promíscua : sobre natureza e paisagem. Finisterra, v. 37, n. 74, p. 141-147, 2001.

LIMA, E. L. Análise no Espaço Rn. São Paulo: Editôra Edgard Blücher Ltda, 1970, 98 p.

MICHELI, G. Natureza. In Enciclopédia Einaudi, vol. 18 : Natureza- Esotérico/exotérico, Lisboa: Imprensa Nacional Casa da Moeda, 1990, pag: 11-54.

MOURÃO, J. A.; BABO, M. A. Semiótica - Genealogias e Cartografias. Coimbra: MinervaCoimbra, 2007, $245 \mathrm{p}$.

NAGENDRA, H., GADGIL, M. Biodiversity assessment at multiple scales: linking remotely sensed data with field information. Proc. Natl. Acad. Sci. USA vol. 96, n. 16, pag: 9154-9158, 1999.

NORBERG-SCHULZ, C. Genius Loci: Paysage, Ambience, Arquitecture. Oslo : Pierre Mardaga Éd., 1976, $213 \mathrm{p}$.

PEREIRA, M. F. R. A Geografia no pensamento filosófico. Mercator, ano 5, n. 10, p. 31-37, 2006.

PETITOT-COCORDA, J. Physique du Sens - De la Théorie des Singularités aux Structures Sémio-narratives. Paris : Éditions du Centre National de la Recherche Scientifique, 1992, 449 p.

RIBEIRO, O. Paisagens, regiões e organização do espaço (com nota introdutória de Carlos Alberto Medeiros). Finisterra v. 36, n. 72, p. 27-35, 2001.

RIITTERS, K. H; WICKHAM, J. D.; WADE, T. G. An indicator of forest dynamics using a shifting landscape mosaic. Ecological Indicators vol. 9, 2009, p. 107-117.

RODRIGUES, M. F. F. Paisagens, geossímbolos e dimensões da cultura em comunidades quilombolas. Fortaleza: Mercator, v. 10, n. 22, p. 103-121, 2011.

RONCAYOLO, M. Território. Enciclopédia Einaudi, vol. 8 : Região, Lisboa: Imprensa Nacional Casa da Moeda, 1986, p. 262-290.

SANTOS, M. A Natureza do Espaço:Técnica e Tempo; Razão e Emoção. São Paulo: Edusp, 2002, 384p. SANTOS, M. Metamorfoses do Espaço Habitado. São Paulo: Hucitec, 1988, 28 p.

SANTOS, M. Técnica, Espaço, Tempo - Globalização e Meio Técnico-científico-informacional. São Paulo: Edusp, 1994, 176 p.

SAUSSURE, F. Curso de Linguística Geral ( $8^{a}$ ed.). Lisboa: Publicações D. Quixote Lda, 1999, 392 p.

SCHNITZLER, A.L'intérêt du modèle architectural dans l'analyse de la biodiversité forestière. Application à la gestion des réserves naturelles rhénanes. Rev. For. Fr. v. LIII (numéro spécial), p. 217-225, 2001.

SMALL, J; WITHERICK, M. Dicionário de Geografia. Lisboa: Publicações D. Quixote, 1992,

SPRINGER, K. S. A concepção de natureza na geografia. Mercator, v. 9, n. 18, p. 159-170, 2010. 
THOM, R. Modèles Mathématiques de la Morphogénèse (2 ème ed.). Paris : Christian Bourgois Éditeur, 1980, $315 \mathrm{p}$.

VITTE, A. C.; da SILVEIRA, R. W. D. Natureza em Alexander von Humboldt: entre a ontologia e o empirismo. Mercator, v. 9, n. 20, p. 179-195, 2010.

WU, J.; HOBBS, R. Landscape ecology: the state-of-the-science. In: J. Wu \& R. Hobbs (eds.) Key Topics in Landscape Ecology, Cambridge: Cambridge University Press, 2007, p: 271-287.

ZILLIG, R. Sobre os múltiplos sentidos de substância: nota acerca de Metafísica Z3, 1028b33-34, Journal of Ancient Philosophy v. I, n.1, p:1-14, 2007.

ZONNEVELD, I. S. Scope and concepts of landscape ecology as an emerging science. In: I. Zonneveld and R.T.T. Forman (eds.) Changing Landscapes: An Ecological Perspective, New York: Springer-Verlag, 1990, p. 1-20.

Trabalho enviado em janeiro de 2013

Trabalho aceito em fevereiro de 2013 